\title{
Late fulminant pulmonary valve endocarditis after the Ross operation
}

\author{
Giovanni Melina, PhD, ${ }^{\mathrm{a}}$ Ismail El-Hamamsy, MD,${ }^{\mathrm{b}}$ Riccardo Sinatra, PhD, ${ }^{\mathrm{a}}$ and Magdi H. Yacoub, FRS, ${ }^{\mathrm{b}}$
}

Rome, Italy, and London, United Kingdom

Pulmonary autografts and left- and right-sided homografts are known for their resistance to early and late infection, which has stimulated their use in patients with active acute endocarditis. ${ }^{1}$ We report the case of a late pulmonary endocarditis after the Ross operation.

\section{CLINICAL SUMMARY}

A 40-year-old man who had previously undergone a Ross operation, presented 7 years after the original operation with fever, shortness of breath, and oliguria. There was no history of recent dental treatment or other invasive procedures. The patient had a stable family background with no history of intravenous drug use at any time. Blood cultures grew Staphylococcus aureus. Thoracic computed tomography showed multiple lung abscesses (Figure 1). Despite antibiotic therapy, his symptoms worsened. Echocardiography showed a large vegetation of the homograft in the pulmonary position. Pulmonary homograft endocarditis was diagnosed, caused by $S$. aureus late after a Ross operation and complicated by immunocomplex glomerulonephritis and lung septic emboli.

The patient underwent urgent surgical excision of the infected valve, which was replaced by a cryopreserved homograft after a period of antibiotic and corticosteroid therapy and hemodialysis. The postoperative period was uneventful, and he made a quick recovery and was discharged on the fourteenth postoperative day.

\section{DISCUSSION}

Isolated infection of the pulmonary valve is rare, but it shares clinical and microbiological features with the more common tricuspid endocarditis. ${ }^{2}$ The first specific clinical manifestations often mimic a pulmonary infection caused by pulmonary septic emboli from the pulmonary valve, thus delaying appropriate and aggressive management strategies. Therefore, careful echocardiographic evaluation of the pulmonary valve should be carried out in all patients

\footnotetext{
From the Department of Cardiac Surgery, ${ }^{\text {a }}$ University of Rome, Italy; and National Heart and Lung Institute, ${ }^{\mathrm{b}}$ Imperial College, London, United Kingdom. Disclosures: None.

Received for publication Feb 15, 2009; accepted for publication March 2, 2009; available ahead of print May 1, 2009

Address for reprints: Magdi H. Yacoub, FRS, National Heart and Lung Institute, Imperial College, Harefield, Middlesex UB9 6JH, United Kingdom (E-mail: m. yacoub@imperial.ac.uk).

J Thorac Cardiovasc Surg 2010;139:e99-100

$0022-5223 / \$ 36.00$

Copyright (c) 2010 by The American Association for Thoracic Surgery

doi:10.1016/j.jtcvs.2009.03.001
}

with suspected infective endocarditis (IE), especially those with prior surgery or known risk factors for right-sided IE.

A precipitating factor needs to be present for IE to develop at the pulmonary position (intravenous drug use, catheterization, valve dysfunction). ${ }^{2}$ In the absence of these risk factors, the cause of pulmonic IE might be similar to that observed on a normal pulmonary valve.

Although circulating immune complexes are frequent in patients with IE, renal failure is less commonly clinically manifest. ${ }^{3}$ The risk of immune-complex glomerulonephritis is higher with $S$. aureus IE and increases with the duration of the disease but generally resolves with eradication of the underlying infection and recovery of good hemodynamics.

\section{Timing of Operation}

Guidelines to aid in decision making in this regard seem to be valve-specific with few data applying to the pulmonary valve. ${ }^{4}$ Decision-making relies heavily on the attending team's experience and judgment and ought to be tailored to each patient's status. All key elements that need to be factored are listed in Table 1. After an initial course of appropriate intravenous antibiotic therapy, surgical intervention has to be considered for the following reasons. First, S. aureus IE is aggressive and the operation may salvage the autograft in the left side before it is infected. Second, the best way to reverse the patient's renal dysfunction is by eliminating the precipitating factor; therefore, early intervention helps to avoid prolonged hemodialysis (indwelling catheters). The patient usually regains normal renal function immediately after surgery. Finally, medical treatment alone may not help in improving the patient's hemodynamic status.

\section{Surgical Technique}

In addition to all the necessary precautions pertaining to redo surgery in an infected patient and the meticulous extensive debridement of all infected tissue, 3 issues need to be addressed. First, the cardiopulmonary bypass montage has to be predetermined. Although clamping the aorta is acceptable, it is preferable to avoid aortic manipulation in such cases and perform surgery on a fibrillating heart with peripheral bypass. The right heart is vented through the right atrial appendage. This approach has the advantage of avoiding any cannulae or extra sutures. The second issue regards whether to explore the pulmonary autograft in the aortic position at the time of surgery. On the basis of echocardiographic findings showing perfect valvular function, considering the long expected lifetime of autografts and the current state of the 

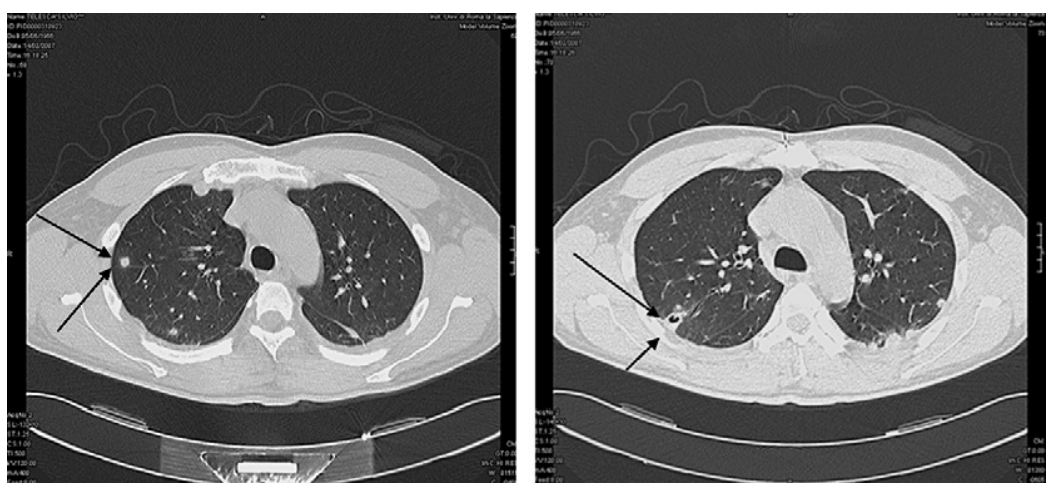

FIGURE 1. Preoperative computed tomography scan showing a pulmonary infiltrate mimicking pneumonia, which is likely secondary to septic emboli.

TABLE 1. Key elements for timing of surgery in patients with rightsided infective endocarditis

- Infecting organism (esp. Staphylococcus aureus and Gram-negative bacilli)

- Secondary heart failure

- Severity of valvular dysfunction

- Response to appropriate antibiotic therapy

- Presence of abscesses, fistulae, pseudoaneurysms, or local extension

- Pulmonary septic emboli, abscesses, or cavitations

- Systemic involvement (DIC, acute renal failure)

$D I C$, Disseminated intravascular coagulopathy.

patient, it is preferable to avoid any unnecessary prolongation of the procedure. Finally, a pulmonary homograft is used to produce least turbulence, and these valves are considered the best substitute for the pulmonary valves.

\section{CONCLUSIONS}

Despite the remarkable resistance of pulmonary homografts to infection in the context of the Ross procedure, this case illustrates the importance of meticulous echocardiographic examination of all valves to eliminate endocarditis. Pulmonary valve endocarditis often presents insidiously and mimics pulmonary infections, therefore warranting a high degree of suspicion. Finally, timing of surgical intervention is critical for the patient's overall prognosis and for protection of the unaffected pulmonary autograft.

\section{References}

1. Yacoub MH, Klieverik LM, Melina G, Edwards SE, Sarathchandra P, Bogers AJ, et al. An evaluation of the Ross operation in adults. J Heart Valve Dis. 2006;15: 531-9.

2. Kang N, Smith W, Greaves S, Haydock D. Pulmonary valve endocarditis. N Engl J Med. 2007;356:2224-5.

3. Zeledon JI, McKelvey RL, Servilla KS, Hofinger D, Konstantinov KN, Kellie S, et al. Glomerulonephritis causing acute renal failure during the course of bacterial infections. Histological varieties, potential pathogenetic pathways and treatment. Int Urol Nephrol. 2008;40:461-70.

4. Bonow RO, Carabello BA, Chatterjee K, de Leon AC Jr, Faxon DP, Freed MD, et al. 2008 Focused update incorporated into the ACC/AHA 2006 guidelines for the management of patients with valvular heart disease. Circulation. 2008;118: e523-661.

\title{
Subepicardial congenital vascular malformation mimicking a bulky tumor with severe compression of the right heart chambers
}

\author{
Naser Qedra, MD, ${ }^{\mathrm{a}}$ Takeshi Komoda, MD, ${ }^{\mathrm{a}}$ Marian Kukucka, MD, ${ }^{\mathrm{b}}$ and Roland Hetzer, MD, PhD, ${ }^{\mathrm{a}}$ Berlin, \\ Germany
}

\footnotetext{
From the Departments of Cardiothoracic and Vascular Surgery ${ }^{\mathrm{a}}$ and Anesthesiology, ${ }^{\mathrm{b}}$ Deutsches Herzzentrum Berlin, Berlin, Germany.

Disclosures: None.

Received for publication Feb 13, 2009; accepted for publication Feb 22, 2009; available ahead of print May 1, 2009.

Address for reprints: Naser Qedra, MD, Deutsches Herzzentrum Berlin, Augustenburger Platz 1, 13353 Berlin, Germany (E-mail: qedra@gmx.de).

J Thorac Cardiovasc Surg 2010;139:e100-2

$0022-5223 / \$ 36.00$

Copyright (c) 2010 by The American Association for Thoracic Surgery

doi:10.1016/j.jtcvs.2009.02.039
}

A 52-year-old man was admitted in poor general condition to the emergency department owing to increasing dyspnea and swelling in both legs over 4 weeks. In addition, he had lost about $8 \mathrm{~kg}$ in weight during the past 2 months. The electrocardiogram showed no pathologic findings but left axis deviation. The chest radiograph showed no abnormalities. Transthoracic echocardiography showed an inhomogeneous structure compressing the right atrium (RA) and the right ventricle $(\mathrm{RV})$. The transesophageal echocardiogram showed 